\title{
Very High-Cycle Fatigue and High-Cycle Fatigue of Minor Boron-Modified Ti-6Al-4V Alloy
}

\author{
Masuo Hagiwara ${ }^{1, *}$, Tomonori Kitashima ${ }^{1, *}$, Satoshi Emura ${ }^{2}$, Satoshi Iwasaki ${ }^{3}$ and Mitsuharu Shiwa ${ }^{4}$ \\ ${ }^{1}$ High Temperature Materials Design Group, Research Center for Structural Materials, National Institute for Materials Science, \\ Tsukuba 305-0047, Japan \\ ${ }^{2}$ Corrosion Resistant Alloy Group, Research Center for Structural Materials, National Institute for Materials Science, \\ Tsukuba 305-0047, Japan \\ ${ }^{3}$ Materials Manufacturing Group, Materials Manufacturing and Engineering Station, National Institute for Materials Science, \\ Tsukuba 305-0047, Japan \\ ${ }^{4}$ Non-Destructive Testing Group, Research Center for Structural Materials, National Institute for Materials Science, \\ Tsukuba 305-0047, Japan
}

A refined fully lamellar microstructure with a prior $\beta$ grain size of $\sim 100 \mu \mathrm{m}$ was obtained for a 0.1 mass percent (\%) B-modified Ti-6Al$4 \mathrm{~V}$ alloy. On the other hand, there were no morphological differences in equiaxed microstructures between the B-free and B-modified alloys; both had $\alpha$ grain sizes of about $8 \mu \mathrm{m}$.

The very high-cycle fatigue (VHCF) lifetimes in the regime from $10 \mathrm{E}+6$ to $10 \mathrm{E}+10$ cycles were measured for these microstructures by using hourglass-shaped specimens and an ultrasonic fatigue test machine at a frequency of $20 \mathrm{kHz}$, while high-cycle fatigue (HCF) lifetimes in the regime from $10 \mathrm{E}+4$ to $10 \mathrm{E}+7$ cycles were measured using smooth cylindrical specimens and a hydraulic servo fatigue test machine at $10 \mathrm{~Hz}$ and a fatigue ratio R of 0.1. The VHCF and HCF behaviors of B-modified alloys were found to be highly dependent on both microstructures and the level of applied stress. In the VHCF regime, where applied stress is well below the conventional fatigue threshold, the B-free and B-modified alloys exhibited the same fatigue strength, in other words, the same fatigue lifetime within the same microstructure. A set of fatigue lifetime data for B-free and B-modified alloys with equiaxed microstructures indicated that these alloys had higher fatigue strength than the alloys with lamellar microstructures in the VHCF diagram in the whole cycle range of up to $10 \mathrm{E}+10$ cycles. The overall trend in the HCF lifetime or strength was that the addition of 0.1 mass $\%$ B had either a favorable effect or no influence on the fatigue life, depending on the level of applied stress. Above a certain level, which corresponded to a cycle regime up to about $10 \mathrm{E}+6$ cycles for a lamellar microstructure and up to about $10 \mathrm{E}+7$ cycles for an equiaxed microstructure, the fatigue lifetime was remarkably prolonged by the addition of 0.1 mass $\% \mathrm{~B}$. However, in the regime beyond these cycles, when the stress level decreased, the favorable effect of B was gradually diminished and the HCF lifetime of the B-free and 0.1 mass\% B-modified alloys were coincident in both lamellar and equiaxed microstructures; this coincidence was maintained thereafter. The mechanism for the dependence of the VHCF and HCF strength of the B-modified alloy on microstructures and the level of applied stress is proposed and discussed. [doi:10.2320/matertrans.MT-M2019169]

(Received June 17, 2019; Accepted July 18, 2019; Published September 6, 2019)

Keywords: Ti-6Al-4V alloy, boron addition, microstructure refinement, high-cycle fatigue, very high-cycle fatigue

\section{Introduction}

It is well documented in the literature ${ }^{1-8)}$ that when components and systems are operated at applied stresses well below the conventional fatigue limit of $10 \mathrm{E}+7$ cycles, damage at the microstructural length scale accumulates, leading to subsequent fatigue failure in the very high-cycle fatigue (hereinafter abbreviated to $\mathrm{VHCF}$ ) regime of $10 \mathrm{E}+6$ to $10 \mathrm{E}+9$ cycles. Such a failure in the $\mathrm{VHCF}$ regime is a serious issue, especially for the auto components such as spring coils, cylinder heads and engine blocks, where very low alternating or cyclic stresses operate constantly and the service life extends well into the VHCF regime.

Lightweight and high strength titanium materials are often used for such auto components. Therefore, studies on the VHCF behavior of titanium including analyses of the dependence of VHCF life on microstructures, and analyses of fatigue damage that include observation of fatigue-crack initiation sites are very important from both an industrial and academic point of view.

The addition of a minor amount of boron (B) to titanium alloy produces whisker-like TiB compounds (hereinafter

*Corresponding authors, E-mail: m-hagi@mti.biglobe.ne.jp, KITASHIMA.

Tomonori@nims.go.jp abbreviated to $\mathrm{TiB})$ during the solidification process. ${ }^{9-16)}$ These TiB contribute to titanium alloys in two respects: they simplify the manufacturing process and thereby the cost, and they improve the material properties of the manufactured products. ${ }^{8-11)}$ One concern regarding B-modified titanium alloys is that the TiB formed in titanium could cause early initiation of fatigue crack, which would lead to the degradation of fatigue properties. However, Hagiwara et al. demonstrated in 0.1 mass $\%$ B-modified Ti-6Al-4V $\mathrm{V}^{17)}$ and Ti-22Al-11Nb-2Mo-1Fe alloys ${ }^{18)}$ that the fatigue cracks originated neither from the $\mathrm{TiB} /$ matrix interface nor from the TiB itself but rather from shear fractures across microstructural units such as colonies or spherical $\alpha$ phases, and that these B-modified alloys exhibit considerably higher high-cycle fatigue (hereinafter abbreviated to HCF) strength than those of B-free alloys. The reduced colony size and the inhibitory effect of $\mathrm{TiB}$ against the expansion of the fatigue initiation area were thought to be responsible for the improved HCF properties of these two alloys with lamellar and equiaxed microstructures, respectively. ${ }^{17)}$

Among the numerous titanium alloys available, the $(\alpha-\beta)$ type Ti-6Al-4V alloy is the most widely used in various industrial applications due to its attractive combinations of mechanical properties. Therefore, the cost-effective minor B-modified Ti-6Al-4V alloy would seem to have good 
potential for applications where VHCF behavior is a main concern.

In the present study, the VHCF life of 0.1 mass $\%$ Bmodified Ti-6Al-4V was measured in comparison with that of a B-free counterpart. To investigate the dependence of the VHCF lifetime or strength on microstructures, alloys having two types of microstructures, i.e., lamellar and equiaxed, were produced by heat treatments. In addition, HCF tests were performed for both the lamellar and equiaxed microstructures across a wider range of applied stresses than in the previous $\mathrm{HCF}$ test ${ }^{17}$ ) in order to confirm that the ability of TiB to inhibit the expansion of the fatigue initiation area was dependent on the level of applied stress during the fatigue test. Failure was analyzed based on the observation of fatigue crack initiation. Finally, based on these experimental results, a tentative mechanism was proposed to account for the dependence of the VHCF and HCF lifetimes of the B-modified alloy on both the microstructures and the level of applied stress.

\section{Experimental}

Cylindrical B-free and 0.1 mass $\%$ B-containing Ti-6Al$4 \mathrm{~V}$ ingots about $70 \mathrm{~mm}$ in diameter and $60 \mathrm{~mm}$ long were prepared via the levitation melting method at the National Institute for Materials Science, Tsukuba, Japan. The alloy ingots were hot-forged to rectangular billets with dimensions of $38 \times 38 \times \sim 150 \mathrm{~mm}^{3}$ at $930^{\circ} \mathrm{C}$ to break the columnar microstructure. These hot-forged billets were then hot barrolled at $930^{\circ} \mathrm{C}$ into $12-\mathrm{mm}$ square bars. Two types of microstructure were generated through two combinations of heat treatments. To generate a fully lamellar microstructure, these hot-rolled bars were annealed at $1050^{\circ} \mathrm{C}$ in the single bcc $(\beta)$-phase region for 1 hour followed by slow cooling at the cooling rate of $0.03 \mathrm{Ks}^{-1}$. To generate an equiaxed microstructure, these hot-rolled bars were annealed at $930^{\circ} \mathrm{C}$ in the $(\alpha-\beta)$ two-phase region followed by slow cooling at the controlled cooling rate of $0.03 \mathrm{Ks}^{-1}$. Finally, all hot-rolled bars were held at $700^{\circ} \mathrm{C}$ for 1 hour to stabilize the microstructures. After these heat treatments, both VHCF and HCF test specimens were machined with the tensile axis parallel to the longitudinal direction of the hot rolled bars.

The ultrasonic fatigue technique can provide fatigue data in the VHCF regime in a time-efficient manner. ${ }^{1)}$ In the present study, therefore, the VHCF behavior of the Bmodified alloy was investigated using this technique with the push-pull mode at a ratio of minimum stress to maximum stress R of -1 . Hourglass-shaped specimens of $18.5 \mathrm{~mm}$ in gage length, $31 \mathrm{~mm}$ in gage diameter and $3.0 \mathrm{~mm}$ in minimum diameter were used, which produced a resonant frequency of $20 \mathrm{kHz}$. The tests were done at room temperature in laboratory air. The details of the VHCF testing technique using these types of specimen configurations have been described elsewhere. ${ }^{5}$ ) To minimize the temperature increases due to heat generation during high frequency cyclic loading, the specimen surface was bombarded continuously, rather than intermittently, with highly compressed air. By this forced-air cooling method, the amount of temperature increase was suppressed to within $10^{\circ} \mathrm{C}$ in the stress amplitude range of up to around $450 \mathrm{MPa}$.
Above this stress amplitude, the amount of temperature increase was more than $50^{\circ} \mathrm{C}$. Therefore, it was considered that the VHCF data for specimens with applied stress amplitude above $450 \mathrm{MPa}$ were not collected at room temperature, and thus they were omitted from the fatigue diagram.

The HCF tests were done at room temperature in laboratory air using a conventional servo-hydraulic testing system with a pull-pull mode at an $\mathrm{R}$ of 0.1 in the loadcontrol mode, and a frequency of $10 \mathrm{~Hz}$. The rest of the hourglass-shaped specimens prepared for VHCF tests were used in the present HCF tests, which made a direct comparison between $\mathrm{VHCF}$ and $\mathrm{HCF}$ data while keeping other factors influencing fatigue data equal.

Microstructural and fractographic observations were made on an optical microscope (OM) and a scanning electron microscope (SEM).

\section{Results and Discussion}

\subsection{Microstructures}

\subsubsection{Ingots and hot-rolled bar microstructures}

Figure 1 shows the effect of the addition of $\mathrm{B}$ on the grain size of levitation-melted Ti-6 Al $-4 \mathrm{~V}$ ingots; B clearly had a beneficial effect on the grain size, which went from around $1000 \mu \mathrm{m}$ to $100 \mu \mathrm{m}$ upon the addition of 0.1 mass $\% \mathrm{~B}$ (Fig. 1(a) and 1(b)). An agglomerated cluster of blackcolored TiB can be seen at the grain boundaries (Fig. 1(c)), and this cluster exerted a pinning effect against grain growth. ${ }^{9,10)}$ The size of each TiB is very small, i.e., typically $2 \sim 5 \mu \mathrm{m}$ in length and $1 \sim 2 \mu \mathrm{m}$ in width.

Tamirisakandala et al. previously discussed the mechanism of $\mathrm{TiB}$ formation and grain refinement in $\mathrm{Ti}$ alloys such as $\mathrm{Ti}-6 \mathrm{Al}-4 \mathrm{~V}$ and $\mathrm{Ti}-6 \mathrm{Al}-2 \mathrm{Sn}-4 \mathrm{Zr}-2 \mathrm{Mo}-0.1 \mathrm{Si}$ via $\mathrm{B}$ addition. ${ }^{19-21)}$ They hypothesized that the mechanism consisted of an effect of constitutional super-cooling caused by the $\mathrm{B}$ rejected from the primary $\beta$-Ti grains into the liquid ahead of the solidification front and its influence on the nucleation and growth rate, rather than any effects of $\mathrm{TiB}$ acting as a nucleating agent.

Figure 2 shows the OM microstructures of the hot barrolled 0.1 mass $\%$ B-modified $\mathrm{Ti}-6 \mathrm{Al}-4 \mathrm{~V}$ alloy in the aspolished condition. The grains were elongated in the rolling direction, and therefore long and narrow bands or streaks of TiB were formed which also aligned along the rolling direction. The spacing between adjacent streaks was irregular, ranging from approximately $30 \mu \mathrm{m}$ to $70 \mu \mathrm{m}$.

\subsubsection{Microstructures after heat treatments}

Figure 3 shows the lamellar microstructures of B-free and 0.1 mass \% B-modified alloys taken on planes parallel to the rolling direction. The B-free alloy showed a typical lamellar microstructure with packets or colonies of similarly aligned $\alpha$-phase lamellae (hcp structure, dark gray phase) and $\beta$ phases (bcc structure, white phase) between lamellae, and a massive $\alpha$-phase at the grain boundaries (Fig. 3(a)). The average colony size was estimated to be about $100 \mu \mathrm{m}$. In the 0.1 mass \% B-modified alloy, due to the presence of streaks of $\mathrm{TiB}$, the growth of $\beta$-grains was blocked when the hot barrolled 0.1 mass $\%$ B-modified alloy was held in the single $\beta$ phase region, and thus there was a marked change in the 

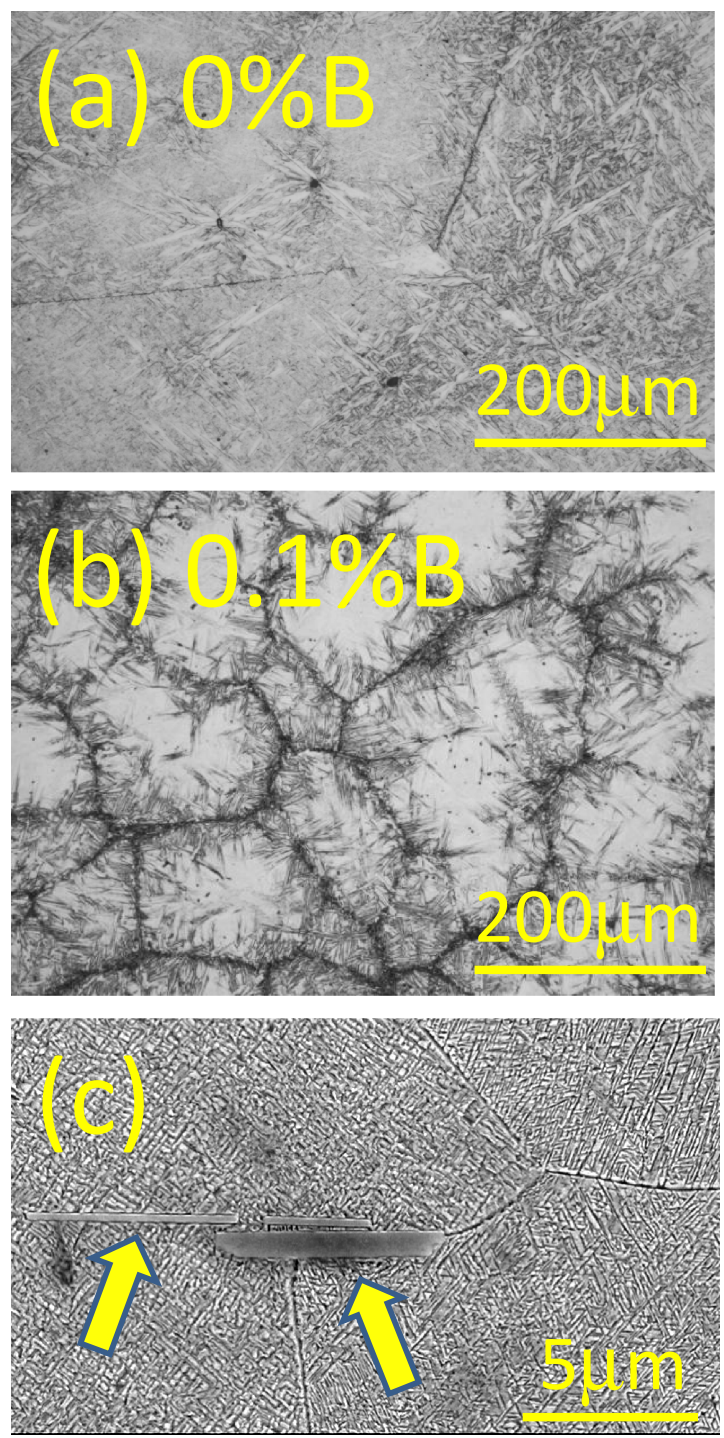

Fig. 1 OM micrographs of (a) B-free and (b) 0.1 mass $\%$ B-modified Ti$6 \mathrm{Al}-4 \mathrm{~V}$ ingots. (c) Higher magnification SEM micrograph of TiB. Arrows indicate TiB.

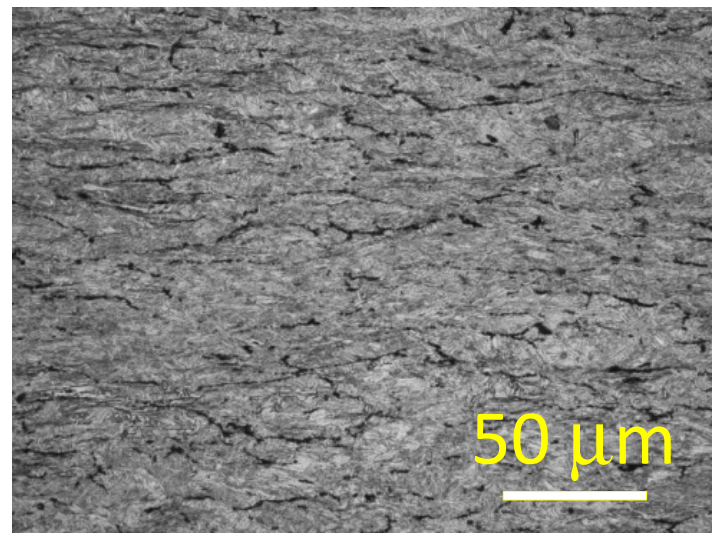

Fig. 2 OM micrographs of the 0.1 mass $\%$ B-modified Ti-6Al-4V alloy under the hot bar-rolled condition.

morphology of the lamellar microstructure. The size of each colony in the $\beta$-grain was estimated to be in the range of $30 \mu \mathrm{m}$ to $70 \mu \mathrm{m}$, since the spacing of adjacent streaks of TiB was within this range. As shown in Fig. 3(b), the length of
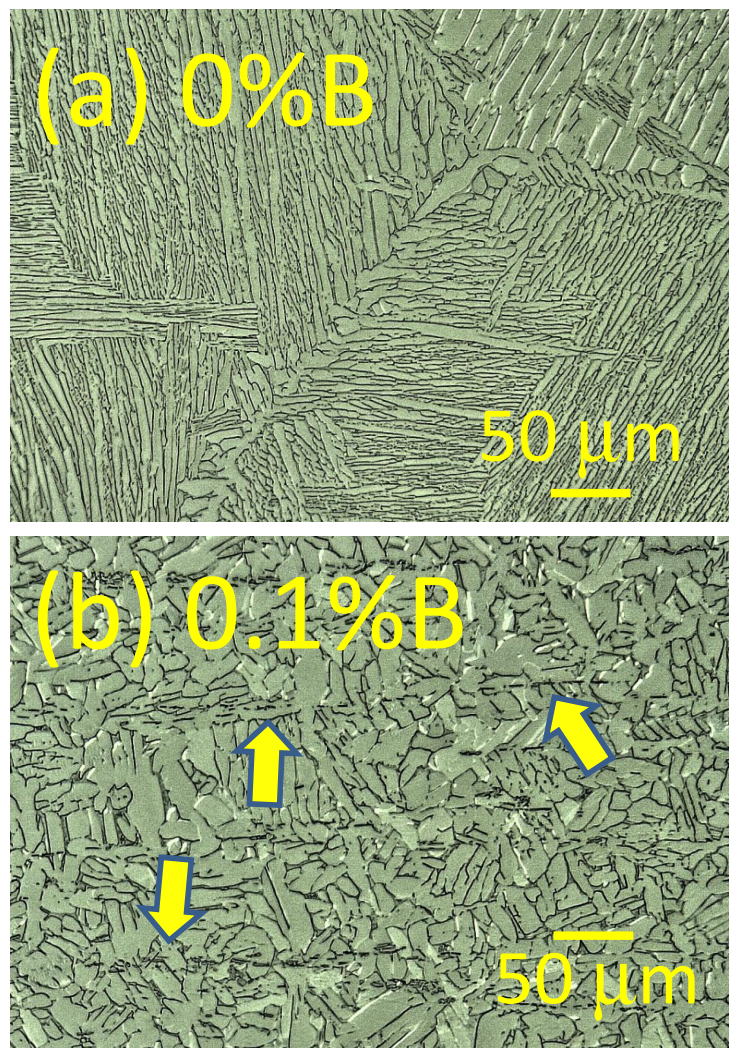

Fig. 3 OM micrographs of the (a) B-free and (b) 0.1 mass $\%$ B-modified Ti-6Al-4V alloys with lamellar microstructures. The arrows indicate TiB.

$\alpha$-phase lamellae within each colony area was significantly shortened, while the width of each $\alpha$-phase lamella was markedly thickened. Morphologically, therefore, the lamellar microstructure of the 0.1 mass\% B-modified alloy resembled an equiaxed microstructure.

Panels $\mathbf{a}$ and $\mathbf{b}$ in Fig. 4 show equiaxed microstructures of the B-free and 0.1 mass\% B-modified alloys, respectively. In contrast to the difference observed for the lamellar microstructures, quite the same equiaxed microstructures with an $\alpha$-grain size of about $8 \mu \mathrm{m}$ were obtained for both alloys. As shown in Fig. 4(b), the spacing of adjacent streaks of TiB was much wider, i.e., $30 \mu \mathrm{m}$ to $70 \mu \mathrm{m}$, than the size of the equiaxed $\alpha$-phases: thus, the growing front of most $\alpha$-phases in the 0.1 mass \% B-modified alloy seemed not to have reached the streaks, which would have resulted in equiaxed $\alpha$-phases that were the same size of the B-free alloy.

\subsection{Tensile properties}

Table 1 shows the tensile data for the present materials after heat treatments. For alloys with lamellar microstructures, the tensile elongation increased from $8 \%$ for the B-free alloy to $16 \%$ by the addition of 0.1 mass $\% \mathrm{~B}$, while the tensile strength (TS) showed almost the same values. The TS of the B-modified alloy with an equiaxed microstructure was a little bit higher than that of the B-free alloy, whereas both alloys exhibited the same elongation of $16 \%$.

\subsection{VHCF properties \\ 3.3.1 VHCF diagrams}

Figure 5 shows the VHCF diagram, i.e., stress amplitude, $\sigma_{\text {amp }}$, vs. number of cycles to failure relationship, of B-free 


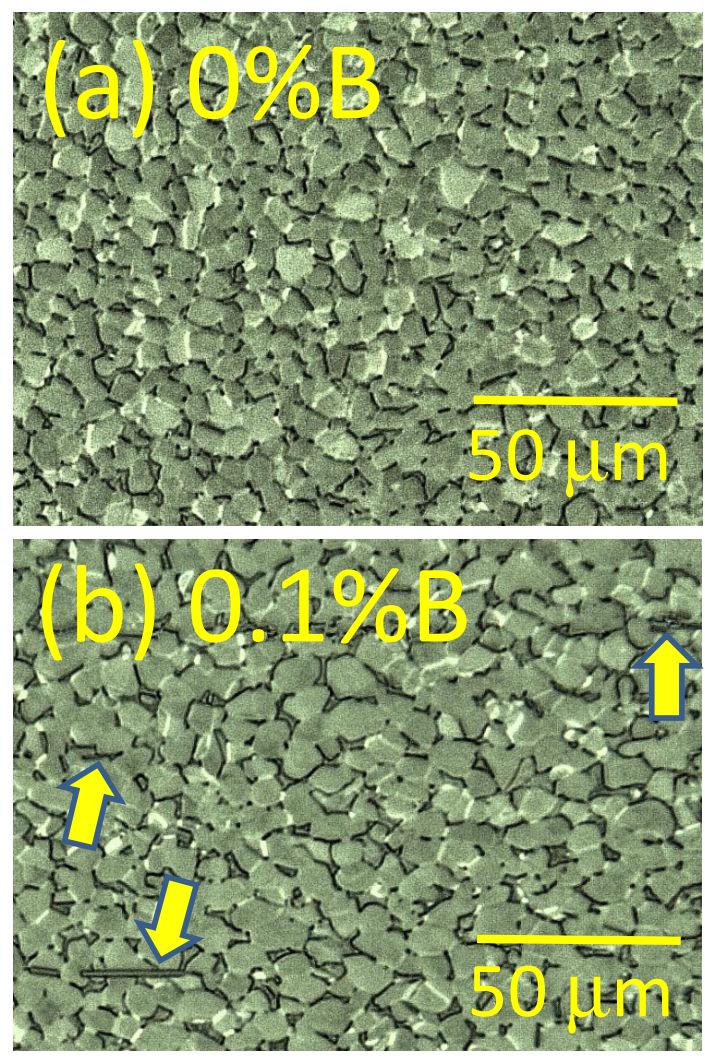

Fig. $4 \mathrm{OM}$ micrographs of the (a) B-free and (b) 0.1 mass $\%$ B-modified Ti-6Al-4V alloys with equiaxed microstructures. The arrows indicate TiB.

Table 1 Tensile properties of the B-free and 0.1 mass $\%$ B-modified Ti$6 \mathrm{Al}-4 \mathrm{~V}$ alloys at room temperature.

\begin{tabular}{|l|l|c|c|c|}
\hline \hline \multicolumn{1}{|c|}{ Alloy } & $\begin{array}{l}\text { Micro- } \\
\text { structure }\end{array}$ & $\begin{array}{c}\text { TS } \\
\mathrm{MPa}\end{array}$ & $\begin{array}{c}\text { U.EL } \\
\%\end{array}$ & $\begin{array}{c}\text { T.EL } \\
\%\end{array}$ \\
\hline \hline \multirow{2}{*}{ Ti-6Al-4V } & \multirow{2}{*}{ Lamellar } & 862.2 & 7 & 8 \\
\cline { 1 - 3 } Ti-6Al-4V-0.1B & & 859.8 & 10 & 16 \\
\hline \multirow{2}{*}{ Ti-6Al-4V } & \multirow{2}{*}{ Equiaxed } & 915.4 & 9 & 16 \\
\cline { 1 - 1 } Ti-6Al-4V-0.1B & & 949.3 & 9 & 16 \\
\hline
\end{tabular}

TS: Tensile Strength, U.EL: Uniform Elongation,

\section{T.EL: Total Elongation}

and 0.1 mass $\%$ B-modified Ti-6Al-4V alloys with lamellar microstructures. The diagram clearly reveals that in the VHCF regime, where applied stress is well below the conventional fatigue threshold, the B-free and B-modified alloys exhibited the same fatigue strength. At an applied stress amplitude of below $300 \mathrm{MPa}$, both alloys were run-outs beyond $10 \mathrm{E}+10$ cycles.

Tensile strength and microstructure are known to be the two main controlling factors in determining HCF strength in titanium alloys, and as the tensile strength increases and the size of microstructural units such as the diameter of an equiaxed $\alpha$-phase in an equiaxed microstructure and the diameter of one colony in a lamellar microstructure decreases, the HCF strength increases. ${ }^{22-24)}$ For the case of

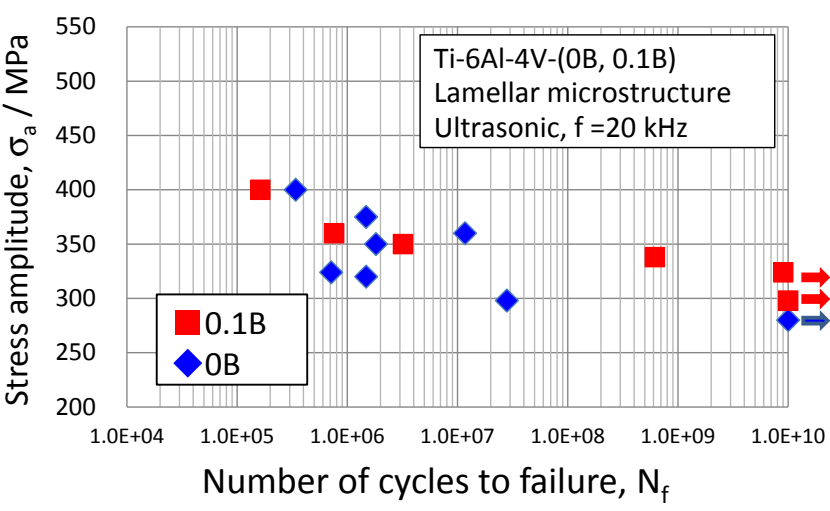

Fig. 5 Very high cycle fatigue (VHCF) diagram of the B-free and 0.1 mass \% B-modified Ti-6Al-4V alloys with lamellar microstructures.

present alloys with lamellar microstructures, the tensile strength of both B-free and 0.1 mass \% B-modified alloys was almost equal, as shown in Table 1 . So, the contribution from a factor associated with tensile strength to the fatigue strength can be eliminated from the consideration. As shown in Fig. 5, the VHCF diagrams of the two alloys overlapped. For the B-free alloy, the average colony size was estimated to be about $100 \mu \mathrm{m}$, as shown in Fig. 3, but it was also estimated to be as low as 30 70 $\mu \mathrm{m}$ for the B-modified alloy. Such a degree of colony-size refinement, from $100 \mu \mathrm{m}$ to $30 \sim 70 \mu \mathrm{m}$, was shown to offer no improvement of fatigue strength, and thus it can be said conclusively that the minor addition of B made no microstructural contribution to VHCF strength.

Figure 6(a) shows the VHCF diagram of B-free and 0.1 mass $\%$ B-modified Ti-6Al-4V alloys with equiaxed microstructures. Similar to the VHCF diagrams for the lamellar microstructures, the VHCF diagrams of both alloys overlapped in the cycle range up to $10 \mathrm{E}+10$ cycles. At an applied stress amplitude below about $400 \mathrm{MPa}$, both alloys were run-outs beyond $10 \mathrm{E}+10$ cycles. Since the tensile strength of the B-modified alloy was a little bit higher than that of the B-free alloy (Table 1), the fatigue ratio of stress amplitude to tensile strength $\left(\sigma_{\mathrm{amp}} / \mathrm{TS}\right)$ was calculated to extract the contribution from the microstructural factor alone. As shown in Fig. 6, the overall trend of the fatigue ratio diagram, i.e., the $\sigma_{\mathrm{amp}} / \mathrm{TS}$ vs. cycles diagram, of $0.1 \mathrm{mass} \%$ B-modified alloy was quite similar to that of the B-free alloy. These two figures indicate that the addition of 0.1 mass $\% \mathrm{~B}$ had no effect on the VHCF behavior of Ti-6Al-4V alloys with equiaxed microstructures.

The VHCF data were compared between the lamellar and equiaxed microstructures by superimposing Fig. 5 and Fig. 6, as shown in Fig. 7, which clearly indicates the dependence of fatigue behavior of the Ti-6Al-4V alloy in the VHCF regime on microstructures. In addition, the set of fatigue data for the B-free and 0.1 mass $\%$ B-modified alloys with equiaxed microstructures is more highly ranked than the set for B-free and B-modified alloys with lamellar microstructures in the VHCF diagram in the whole cycle range of up to $10 \mathrm{E}+10$ cycles.

\subsubsection{Analysis of fatigue crack initiation site}

In all cases, except for the B-free alloy with coarse lamellar microstructure, in which the initiation site was obscured due 

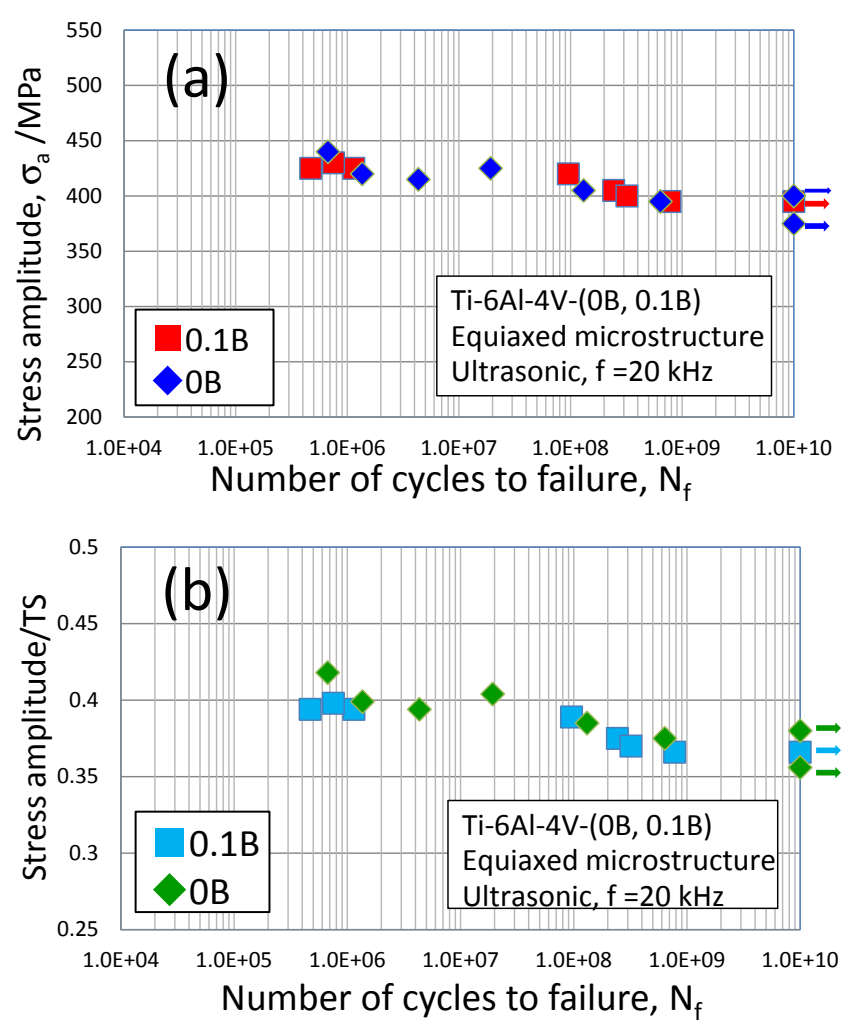

Fig. 6 (a) Very high cycle fatigue (VHCF) diagram and (b) fatigue ratio diagram, i.e., $\sigma_{\mathrm{amp}} / \mathrm{TS}$ vs. number of cycles to failure, of the B-free and 0.1 mass\% B-modified Ti-6Al-4V alloys with equiaxed microstructures.

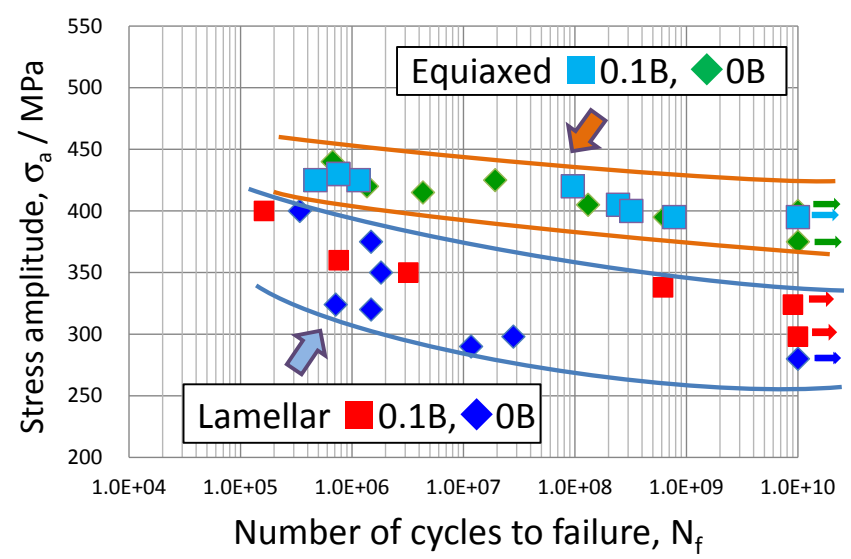

Fig. 7 Comparison of VHCF data between the lamellar and equiaxed microstructures.

to the rough fracture surface morphology, the B-free and 0.1 mass \% B-modified Ti-6Al-4V alloy with lamellar and equiaxed microstructures showed fatigue failure that was initiated not from the surface sites but rather from the subsurface sites. The distance of the sub-surface initiation site from the specimen surface ranged from $30 \mu \mathrm{m}$ to about $300 \mu \mathrm{m}$, and most of the initiation sites were situated adjacent to the specimen surface, i.e., about $50 \mu \mathrm{m}$ away from the surface. Further, it was found that when the sub-surface initiation site was very close to the specimen surface, fatigue fracture surfaces were not deformed and thus the morphology of the fracture surface clearly reflected the underlying

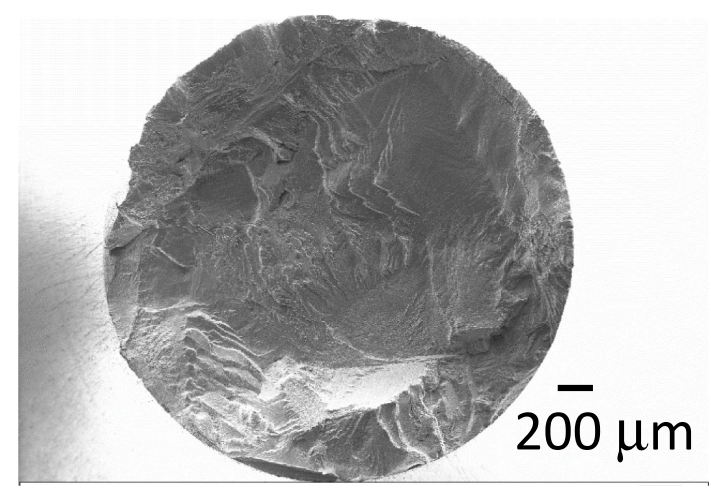

Fig. 8 A typical fatigue fracture surface taken from the B-free Ti-6Al-4V alloy specimen with a lamellar microstructure (stress amplitude, $\sigma_{\mathrm{a}}=$ $300 \mathrm{MPa}$; number of cycles to failure, $N_{\mathrm{f}}=2.802 \mathrm{E}+07$ cycles).

microstructure. This was perhaps less due to constraint at the free surface and in the vicinity of the specimen surface. Accordingly, the force of impact at the time of collision of between the two fatigue fracture surfaces that were newly formed during the VHCF test at a push-pull mode was not particularly strong, and consequently the extent of deformation of the two newly formed fracture surfaces was not significant. In contrast, in the case when the sub-surface fatigue crack initiated far from the specimen surface, the newly formed two fracture surfaces were severely deformed, which indicates that the collision force was more intense, and thus it was difficult to correlate the morphology of fracture surfaces with the underlying microstructure. Such typical fracture surfaces are discussed below.

Figure 8 shows SEM micrographs of the fatigue fracture surface taken from the B-free Ti-6Al-4V alloy with a coarse lamellar microstructure (Fig. 3(a)). There were several large flat facets evident on the fracture surface. The size of each facet ranged from $200 \mu \mathrm{m}$ to $500 \mu \mathrm{m}$, which corresponds well to the size of one colony of similarly aligned lamellae or laths in the lamellar microstructure. Due to this rough morphology of the fracture surface, it was very difficult to identify the fatigue crack initiation site.

The fatigue fracture surface taken from the 0.1 mass $\%$ Bmodified Ti-6Al-4V alloy with refined lamellar microstructures (Fig. 3(b)) exhibited the same rough morphology as the B-free alloy, as shown in Fig. 9. However, the degree of roughness was extremely reduced in the B-modified alloy. The sub-surface fatigue crack initiation site could be easily identified, as indicated by the square box in Fig. 9(a). A few flat facets, each $\sim 50 \mu \mathrm{m}$ in diameter, were present at the fatigue initiation site (Fig. 9(b)). The size of these facets corresponded well to that of the colonies (Fig. 3(b)).

SEM micrographs of fatigue fracture surface of B-free Ti$6 \mathrm{Al}-4 \mathrm{~V}$ alloy with an equiaxed microstructure with fatigue crack initiation site close to and far from the specimen surface are shown in Fig. 10 and Fig. 11, respectively. In the case where the fatigue failure was initiated close to the surface, that is, about $50 \mu \mathrm{m}$ from the specimen surface (Fig. 10(a)), there existed multiple clusters or an agglomerated cluster of flat facets at the initiation site (Fig. 10(b)). The size of each flat facet was about $8 \mu \mathrm{m}$ in diameter, which seems to correspond closely to that of a spherical $\alpha$-phase in 

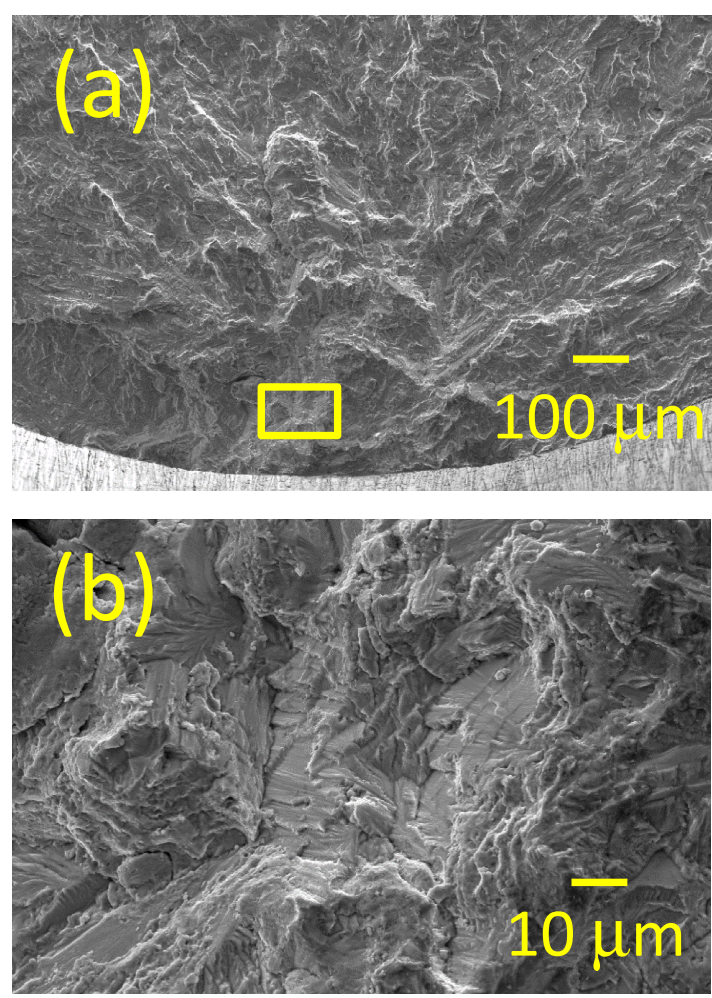

Fig. 9 A typical fatigue fracture surface taken from the B-free Ti-6Al-4V alloy with a lamellar microstructure (stress amplitude, $\sigma_{\mathrm{a}}=350 \mathrm{MPa}$; number of cycles to failure, $N_{\mathrm{f}}=3.200 \mathrm{E}+6$ cycles). (a) Whole view. A square box indicates the fatigue initiation site. (b) Higher magnification SEM micrograph of the fatigue initiation site.
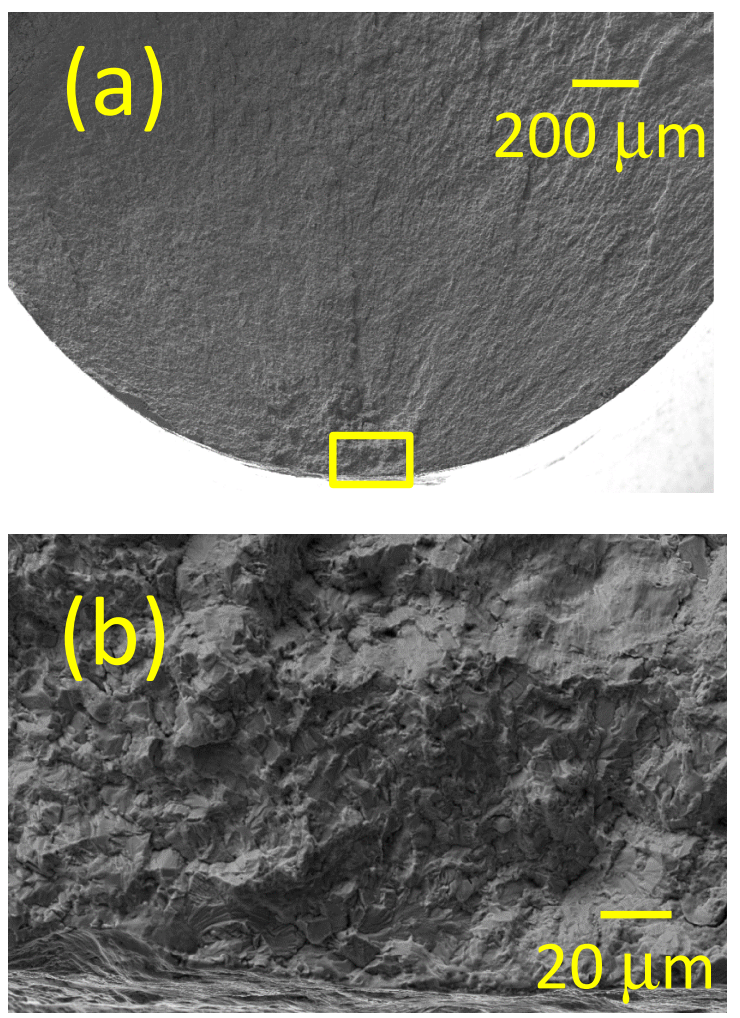

Fig. 10 SEM micrographs of the fatigue fracture surface of the B-free Ti-6Al-4V alloy with an equiaxed microstructure with a fatigue crack initiation site close to the specimen surface (stress amplitude, $\sigma_{\mathrm{a}}=$ $420 \mathrm{MPa}$; number of cycles to failure, $N_{\mathrm{f}}=1.361 \mathrm{E}+6$ cycles). (a) Whole view. A square box indicates the fatigue initiation site. (b) Higher magnification SEM micrograph of the fatigue initiation site.
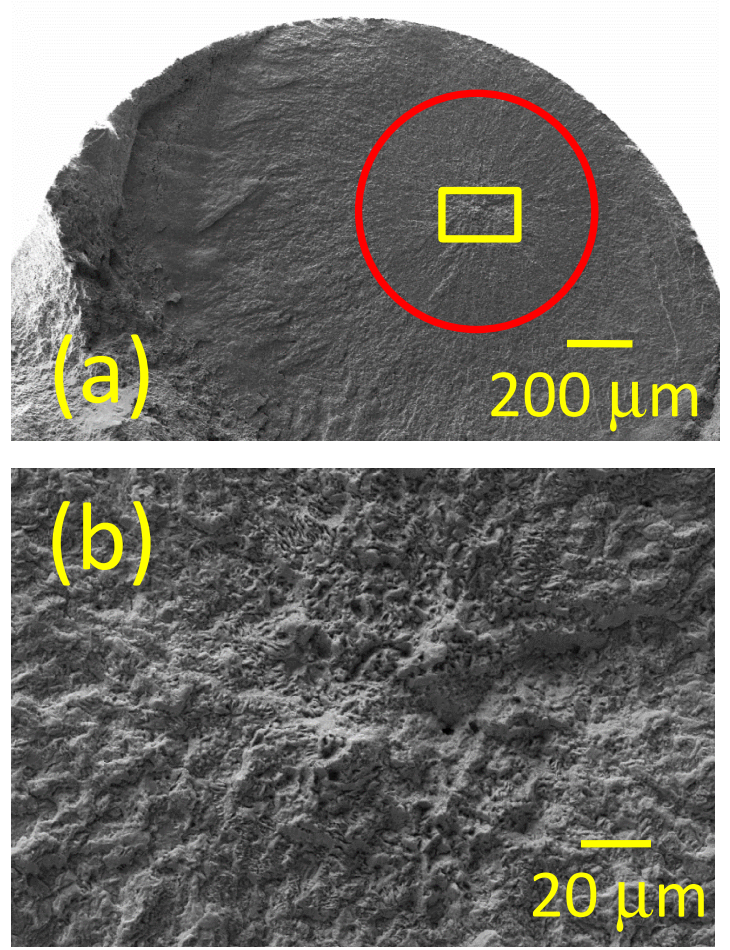

Fig. 11 SEM micrographs of the fatigue fracture surface of the B-free Ti-6Al-4V alloy with an equiaxed microstructure with a fatigue crack initiation site far from the specimen surface (stress amplitude, $\sigma_{\mathrm{a}}=$ $415 \mathrm{MPa}$; number of cycles to failure, $N_{\mathrm{f}}=4.330 \mathrm{E}+6$ cycles). (a) Whole view. A square box indicates the fatigue initiation site and a circle indicates the fatigue propagation area. (b) Higher magnification SEM micrograph of the fatigue initiation site.

the microstructure. This type of multiple-facet initiation has already been reported in Ti-6Al-4V alloys and other titanium alloys by many researchers, and the reason for its occurrence has been discussed extensively. ${ }^{25,26)}$ In the case where the fatigue failure was initiated far from the specimen surface (Fig. 11(a)), the initiation site was highly deformed and thus it was difficult to distinguish an agglomerated cluster of flat facets (Fig. 11(b)). In Fig. 11(a), three stages of HCF fracture process, namely, fatigue crack initiation (Stage I), fatigue propagation (Stage II) and fast fracture (Stage III) can be clearly seen on the fracture surface. The diameters of the initiation stage and propagation region, which is surrounded by a circle, seem to be $100 \sim 200 \mu \mathrm{m}$ and $\sim 800 \mu \mathrm{m}$, respectively.

Figure 12 shows SEM micrographs of the fatigue fracture surface taken from the 0.1 mass $\%$ B-modified alloy with an equiaxed microstructure. The overall morphology of the fatigue fracture surface was quite similar to that of the B-free alloy. In the case where the fatigue failure was initiated close to the surface (Fig. 12(a)), there existed multiple clusters or an agglomerated cluster of flat facets at the initiation site. In the case where the fatigue failure was initiated far from the specimen surface (Fig. 12(b)), the initiation site was highly deformed. Further examinations of the crack initiation site at high magnification indicated no presence of TiB. Thus, it seems reasonable to consider that the fatigue crack was not initiated at TiB itself but rather from the shear fractures across the spherical $\alpha$-phases. 

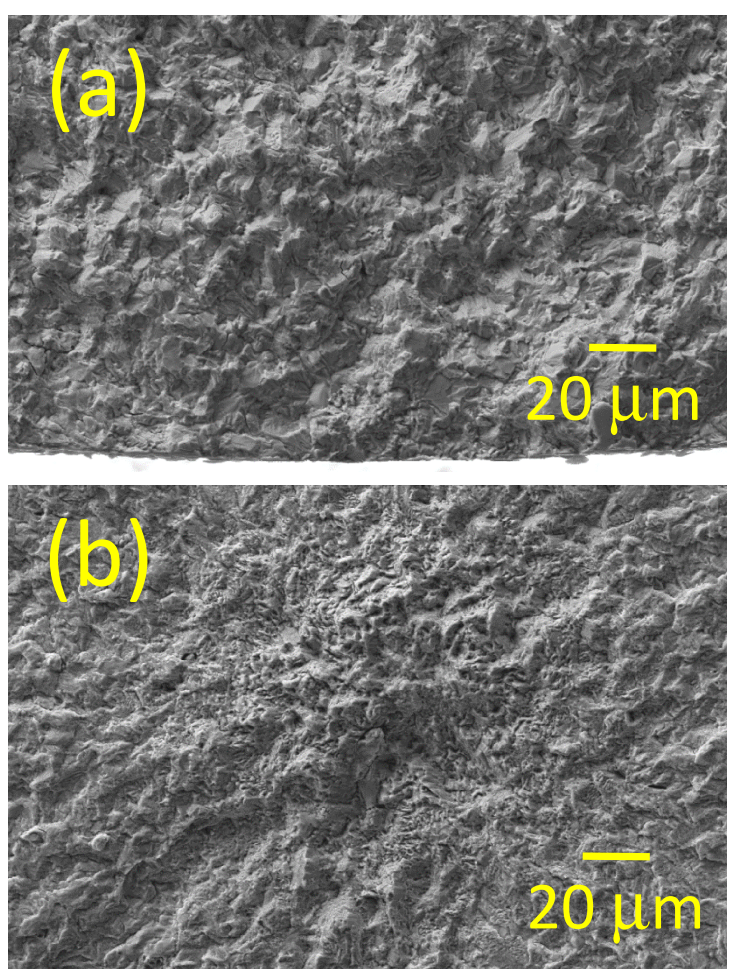

Fig. 12 SEM micrographs of the fatigue fracture surface of the 0.1 mass $\%$ B-modified Ti-6Al-4V alloy with an equiaxed microstructure with a fatigue crack initiation site (a) close to the specimen surface (stress amplitude, $\sigma_{\mathrm{a}}=420 \mathrm{MPa}$; number of cycles to failure, $N_{\mathrm{f}}=9.560 \mathrm{E}+7$ cycles), and (b) far from the specimen surface (stress amplitude, $\sigma_{\mathrm{a}}=$ $405 \mathrm{MPa}$; number of cycles to failure, $N_{\mathrm{f}}=2.434 \mathrm{E}+8$ cycles).

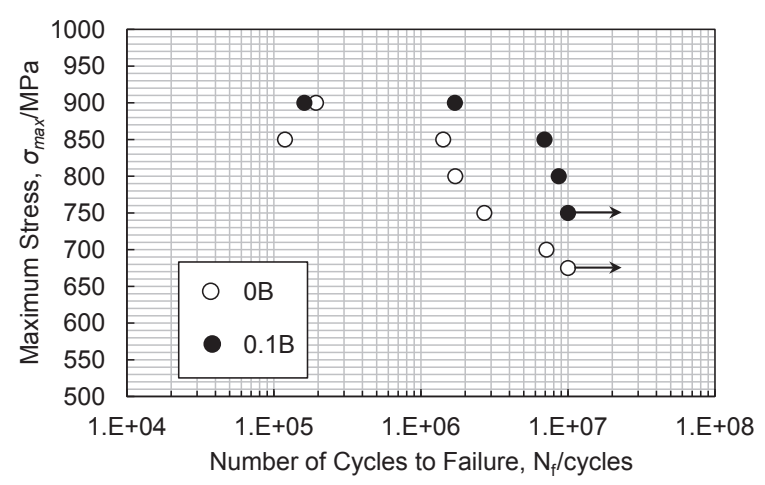

Fig. 13 High cycle fatigue (HCF) diagram of the B-free and 0.1 mass $\%$ Bmodified Ti-6Al-4V alloys with equiaxed microstructures. ${ }^{17)}$

\subsection{HCF properties}

As described above, the B-free and 0.1 mass $\%$ B-modified Ti-6Al-4V alloys exhibited the same fatigue strength in the cycle range of to $10 \mathrm{E}+10$ cycles (See Fig. 5 and Fig. 6), and accordingly, it was found that the addition of 0.1 mass $\% \mathrm{~B}$ had no effect on VHCF behavior. However, contrary to these results, the authors have previously reported that the HCF strength of 0.1 mass $\%$ B-modified Ti- $6 \mathrm{Al}-4 \mathrm{~V}$ alloy ${ }^{17)}$ and $\mathrm{Ti}-22 \mathrm{Al}-11 \mathrm{Nb}-2 \mathrm{Mo}-1 \mathrm{Fe}^{18)}$ at room temperature increased compared to the B-free counterparts. These results are shown in Fig. 13 for an equiaxed microstructure ${ }^{17)}$ and Fig. 14 for a lamellar microstructure. ${ }^{17)}$ For example, the HCF strength at $10 \mathrm{E}+7$ cycles for the alloy with an equiaxed microstructure increased to $750 \mathrm{MPa}$ by the addition of $0.1 \mathrm{mass} \% \mathrm{~B}$, from $650 \mathrm{MPa}$ for the B-free alloy.

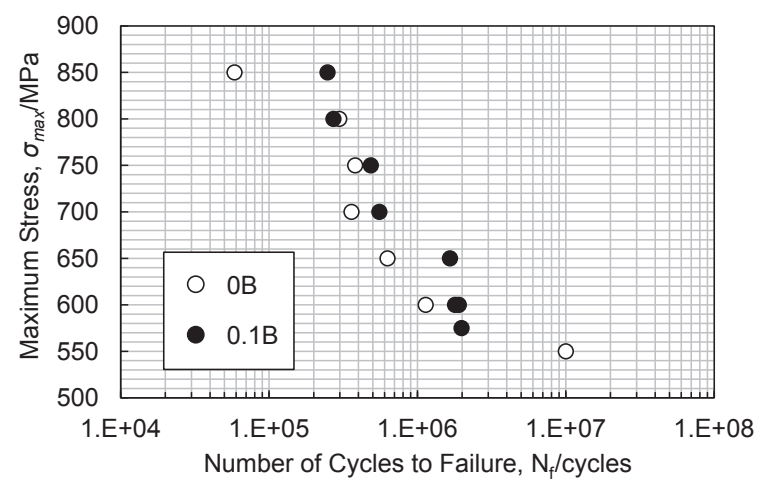

Fig. 14 High cycle fatigue (HCF) diagram of the B-free and 0.1 mass \% Bmodified Ti-6Al-4V alloys with lamellar microstructures. ${ }^{17)}$

By careful examination of Fig. 13 and Fig. 14, it can be seen that the difference in the number of cycles to failure $\left(\mathrm{N}_{\mathrm{f}}\right)$ between the B-free and 0.1 mass \% B-modified alloys decreases as the applied stress decreases. Therefore, it is expected that if the HCF test is performed in a lower range of applied stress, for example in a range of applied stresses below $750 \mathrm{MPa}$ as in Fig. 13, this difference will become small or will even approach zero.

To examine this hypothesis, we have performed an HCF test for both the lamellar and equiaxed microstructures in wider ranges of applied stresses than were used in the previous HCF test; ${ }^{17}$ for this purpose we used the remaining hourglass-shaped specimens which had been prepared for the measurement of VHCF strength of the present B-free and 0.1 mass $\%$ B-modified Ti-6Al-4V alloys.

\subsubsection{Previous results on the HCF properties of 0.1 mass \% B-modified Ti-6Al-4V}

Before showing the results of the present HCF tests, we will briefly discuss our previous results on the $\mathrm{HCF}$ properties of the 0.1 mass $\%$ B-modified Ti-6Al-4V and the role of TiB in improving HCF strength. ${ }^{17)}$ These previous findings will help us analyze the fatigue mechanism of the 0.1 mass \% B-modified Ti-6Al-4V alloy.

The ingot used in the earlier experiments was prepared by the levitation melting method at the National Institute for Materials Science, and the same forging process, hot-bar rolling process and heat treatment processes as used in the present study were applied to this alloy. Therefore, the lamellar and equiaxed microstructures were identical to those of the present heat-treated materials. For HCF tests, smooth cylindrical specimens of $4.5 \mathrm{~mm}$ diameter and $14 \mathrm{~mm}$ gauge length were machined from hot-rolled bars, and thus the tensile axis of the specimens were parallel to the longitudinal direction of the hot-rolled bars.

For the case of the B-free and 0.1 mass \% B-modified alloys with equiaxed microstructures, we predicted that the HCF strength of the 0.1 mass $\%$ B-modified alloy would coincide with that of the B-free alloy, since both alloys showed almost the same $0.2 \%$ proof stress and tensile strength and microstructures. ${ }^{17)}$ However, contrary to this prior prediction, the 0.1 mass $\%$ B-modified alloy showed a considerably higher HCF strength in the whole cycle range examined. For example, the HCF strength at $10 \mathrm{E}+7$ cycles increased to $750 \mathrm{MPa}$ by the addition of 0.1 mass $\% \mathrm{~B}$, from $675 \mathrm{MPa}$ for the B-free alloy, as shown in Fig. 13. ${ }^{17)}$ 
In the previous paper, we attributed this improvement of HCF strength in the equiaxed microstructure to the inhibitory effect of TiB against fatigue crack propagation. The reason for this speculation was as follows:

Among three stages of the HCF fracture process, i.e., fatigue crack initiation (Stage I), fatigue crack propagation (Stage II) and fast fracture (Stage III), the majority of the fatigue life (more than 90\%) is spent in Stage I. ${ }^{27}$ ) So a discussion on the mechanism of fatigue improvement for the B-modified alloy should be focused on the Stage I.

As shown in Fig. 11(b) and Fig. 2 of the present paper, the diameter of the fatigue crack initiation area and the spacing of bands or streaks of TiB in the hot bar-rolled specimens are $100 \sim 200 \mu \mathrm{m}$ and $30 \sim 70 \mu \mathrm{m}$, respectively. Since both the whisker-like TiB itself and the streaks of TiB align parallel to the longitudinal direction of the HCF test specimen, and the fatigue crack during the fatigue test proceeds perpendicularly to the $\mathrm{TiB}$ or streaks of $\mathrm{TiB}$, there is a good possibility that the fatigue initiation front would encounter TiB or streaks of TiB multiple times. During this process, the TiB or streaks of TiB would have strong potential to block the expansion of the fatigue initiation area, which would have the effect of slowing the process of the fatigue initiation area reaching a critical size of 100 to $200 \mu \mathrm{m}$, and thus lead to a prolonged fatigue life compared to that of the B-free specimen. On the other hand, if the fatigue crack proceeds parallel to the orientation of the $\mathrm{TiB}$ or the streaks of $\mathrm{TiB}$, the fatigue crack front would be unlikely to encounter $\mathrm{TiB}$ or streaks of $\mathrm{TiB}$ frequently, which would result in a minor improvement of fatigue strength.

To confirm our hypothesis that TiB would inhibit the fatigue crack propagation and its orientation dependence of TiB, we first prepared 70-mm-wide and 12-mm-thick rectangular plates by uniaxially hot sheet-rolling levitationmelted B-free and 0.1 mass \% B-containing cylindrical Ti$6 \mathrm{Al}-4 \mathrm{~V}$ ingots, which subsequently received the same heat treatment as the hot bar-rolled materials to produce equiaxed microstructures. From these sheets, we prepared two types of HCF test specimens. These were fatigue specimens with longitudinal directions parallel (denoted as L-specimen) and fatigue specimens with longitudinal directions perpendicular (denoted as T-specimen) to the rolling direction.

The results of HCF tests showed a higher degree of fatigue improvement in the L-specimens than in the T-specimens, which supported our speculation that the interaction between the fatigue initiation area and the $\mathrm{TiB}$ or streaks of $\mathrm{TiB}$ is much stronger when the TiB or streaks of TiB are aligned parallel to the longitudinal axis of the fatigue specimen due to the increased likelihood of TiB or streaks of TiB intersecting with the moving front of the fatigue initiation area. Our speculation that the $\mathrm{TiB}$ or streaks of $\mathrm{TiB}$ in the equiaxed microstructure would inhibit the expansion of the fatigue initiation area was thus confirmed experimentally.

Similarly, the 0.1 mass $\%$ B-modified alloy with lamellar microstructures showed a slightly higher HCF strength, i.e., a longer HCF life, than that of the B-free alloy in the cycle range up to $10 \mathrm{E}+6$ cycles. For example, an increase in $\mathrm{HCF}$ strength of about $50 \mathrm{MPa}$ was obtained at $10 \mathrm{E}+6$ cycles, as shown in Fig. 14. ${ }^{17}$ )
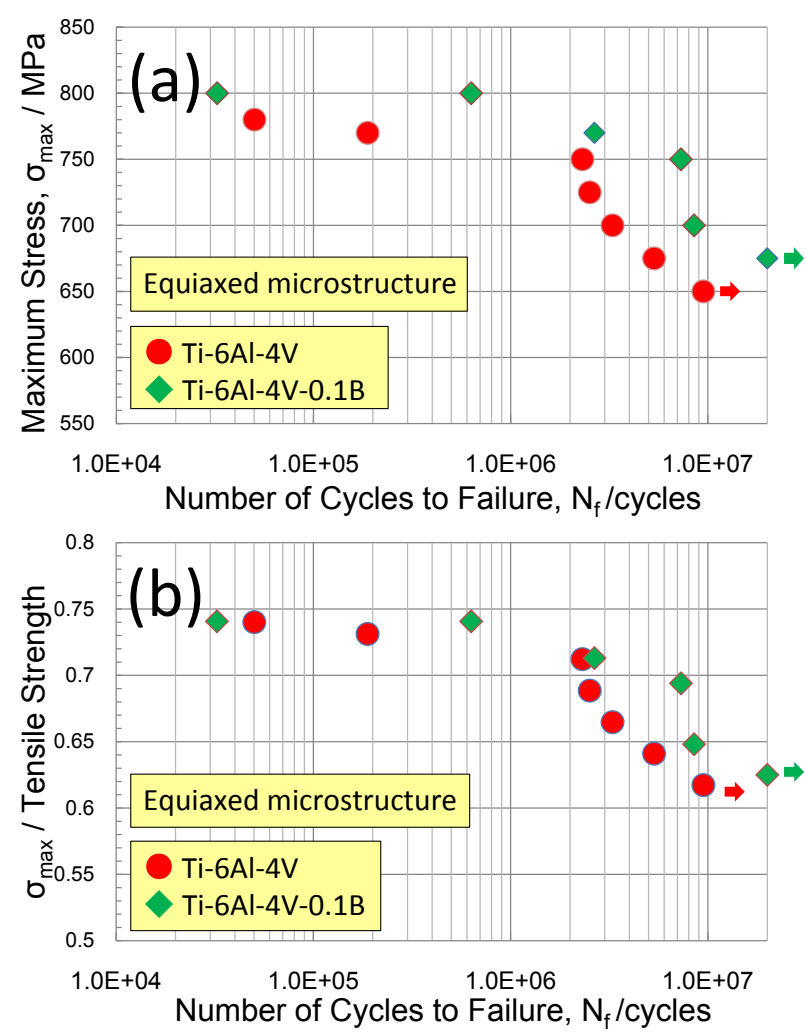

Fig. 15 (a) High cycle fatigue (HCF) diagram and (b) fatigue ratio diagram, i.e., $\sigma_{\max } / \mathrm{TS}$ vs. number of cycles to failure, of the B-free and 0.1 mass $\%$ B-modified Ti-6Al-4V alloys with equiaxed microstructures.

\subsubsection{HCF diagrams with a wider range of applied stress}

The present results of the HCF tests done for the B-free and 0.1 mass $\%$ B-modified Ti-6Al-4V alloys with equiaxed microstructures are shown in Fig. 15(a). The most noticeable feature seen from this figure is that the improvement of HCF strength by the minor addition of $\mathrm{B}$ was dependent on the applied stress, $\sigma_{\max }$. Namely, both alloys revealed quite different HCF diagrams depending on the $\sigma_{\max }$. At an applied stress level above $650 \mathrm{MPa}$, the 0.1 mass $\%$ B-modified alloy showed prolonged HCF life compared to the B-free alloy. In other words, the 0.1 mass $\%$ B-modified alloy showed higher $\mathrm{HCF}$ strength in the cycle range of up to $2.0 \mathrm{E}+06$ cycles. To describe the HCF diagrams in the $\sigma_{\max }$ range above $650 \mathrm{MPa}$ more explicitly, the difference of the HCF lives between the B-free and 0.1 mass $\%$ B-modified alloys decreased with a decrease in the applied stress, becoming almost zero at around $650 \mathrm{MPa}$. In the stress range below $650 \mathrm{MPa}$, the HCF lives of both alloys seemed to be continuingly coincident. Since the tensile strength (TS) of the B-modified alloy was a little bit higher than that of the B-free alloy (Table 1), the fatigue ratio of maximum stress to tensile strength $\left(\sigma_{\max } / \mathrm{TS}\right)$ was calculated to exclude the contribution of the strength factor and thus to extract the contribution from the microstructural factor alone. As shown in Fig. 15(b), the difference in the fatigue ratio, $\sigma_{\max } / \mathrm{TS}$, between the two alloys was approaching zero at around a fatigue ratio of 0.6 , and it was supposed that the fatigue ratios of the two alloys would roughly coincide below this ratio of 0.6. 

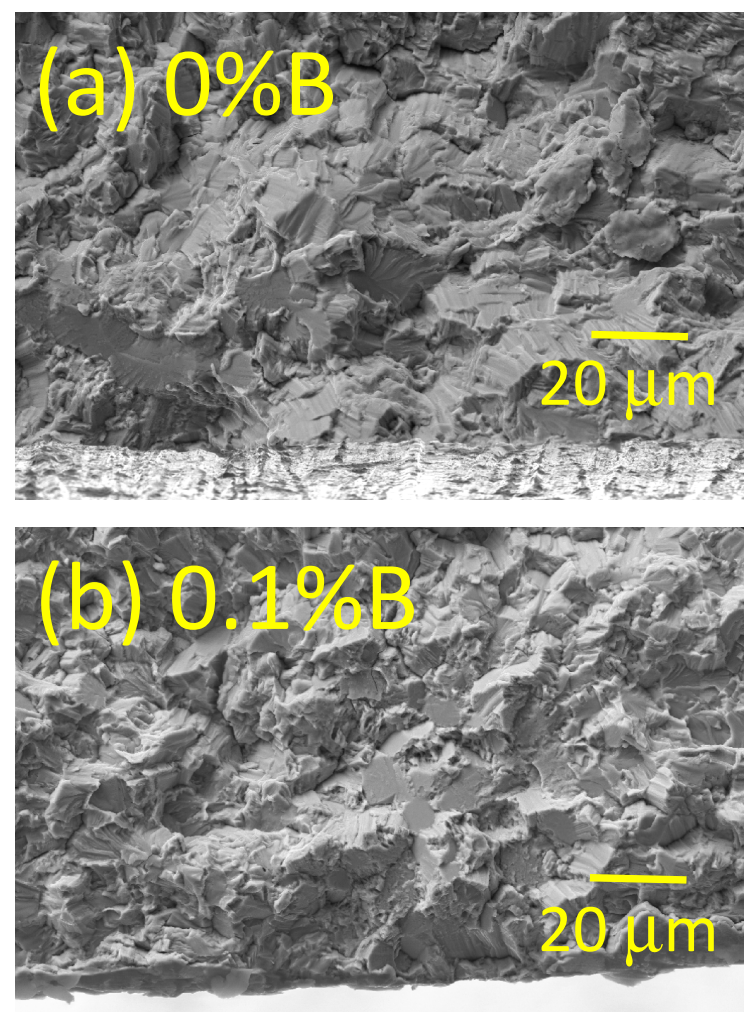

Fig. 16 SEM micrographs of fatigue fracture surfaces taken from the Bfree and 0.1 mass $\%$ B-modified alloys with equiaxed microstructures.

Figure 16 shows SEM micrographs of fatigue fracture surfaces taken from the B-free and 0.1 mass $\%$ B-modified alloys with equiaxed microstructures. The overall morphology of the fatigue fracture surface is highly similar for both alloys, and multiple clusters or an agglomerated cluster of flat facets that are traces of fracture of equiaxed $\alpha$-phases were observed at the initiation site. Higher magnification of the crack initiation site on the SEM micrograph indicated that TiB was not present in the present 0.1 mass $\%$ B-modified alloy.

The results of the HCF tests done for B-free and 0.1 mass\% B-modified Ti-6Al-4V alloys with lamellar microstructures are shown in Fig. 17(a). As was the case for alloys with equiaxed microstructures, the improvement of HCF strength by the minor addition of $\mathrm{B}$ had a dependence on the applied stress, $\sigma_{\max }$. At a stress level above $550 \mathrm{MPa}$, the 0.1 mass $\%$ B-modified alloy showed a prolonged HCF life compared to the B-free alloy. In other words, the 0.1 mass $\%$ B-modified alloy showed higher HCF strength in the cycle range of up to $2.0 \mathrm{E}+06$ cycles. In the stress range below $550 \mathrm{MPa}$, the HCF lives of the two alloys were completely coincident. Figure 17(b) shows the HCF ratio diagram, i.e., $\sigma_{\max } / \mathrm{TS}$ vs. the number of cycles to failure. Since the difference in TS between the B-free and 0.1 mass\% B-modified alloys was not so marked, the HCF ratio diagram showed the same feature as that for Fig. 17(a).

\subsubsection{Mechanism of fatigue improvement}

The present study revealed that the HCF improvement by the addition of a minor amount of B occurs at above certain applied stress levels.

For an equiaxed microstructure, based on the experimental evidence, ${ }^{17}$ this fatigue improvement is almost certainly
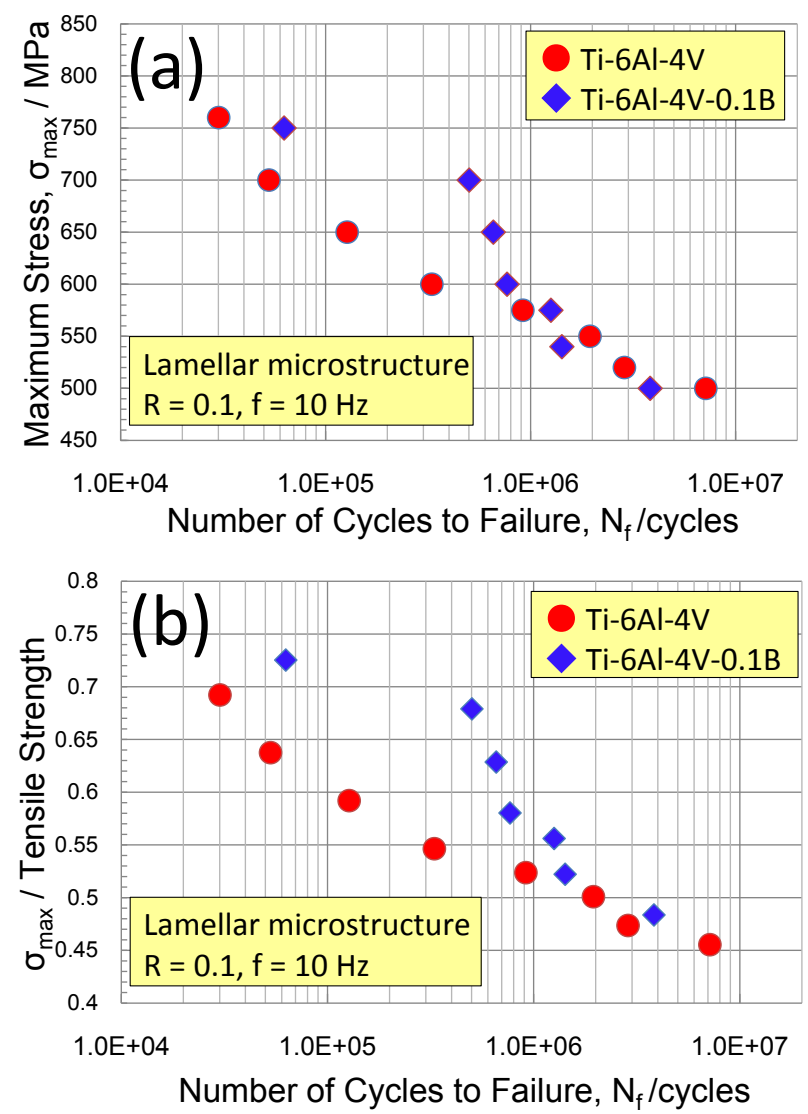

Fig. 17 (a) High cycle fatigue (HCF) diagram and (b) fatigue ratio diagram, i.e., $\mathrm{s}_{\max } / \mathrm{TS}$ vs. number of cycles to failure, of the B-free and 0.1 mass \% B-modified Ti-6 Al-4V alloys with lamellar microstructures.

attributed to the inhibitory effect of TiB against fatigue crack propagation.

In the case of a lamellar microstructure, we previously considered $^{17)}$ that the reduced colony size associated with the addition of $\mathrm{B}$, which corresponds to the shorter slip length, was mainly responsible for the higher HCF strength exhibited by the 0.1 mass\% B-modified Ti-6Al-4V alloy with lamellar microstructure. However, it was found in the present study that the addition of 0.1 mass $\% \mathrm{~B}$ made no contribution to VHCF strength, since the VHCF diagrams of the two alloys overlapped. Rather, it is reasonable to consider that the fatigue improvement was caused by the inhibitory effect of TiB against fatigue crack propagation just as in an equiaxed microstructure.

The extent of fatigue improvement was found to decrease as the level of applied stress decreased, and at an applied stress level below a certain critical value, no contribution to the improvement was observed. So another question to be resolved is why the improvement of HCF strength by the addition of 0.1 mass $\%$ B was dependent on the applied stress? Although the exact mechanism responsible for this behavior requires further investigation, one possible explanation might be that when the application of stress during the fatigue test is sufficiently high, the impact between the front of the moving fatigue crack and a TiB or streaks of TiB will generate greater backward force to the moving fatigue crack, thereby slowing the expansion of the fatigue crack front, which in turn would prolong the HCF life. On the other hand, 
when the applied stress is lower, the impact force and backward force will not be as high, causing no delayed movement of the fatigue crack front and leading to the coincidence between the fatigue lives of the B-free and Bmodified alloys.

\section{Conclusion}

The addition of boron (B) to titanium alloy produces whisker-like TiB compounds during the solidification process. In the present study, the very high-cycle fatigue (VHCF) behavior in the regime from $10 \mathrm{E}+6$ to $10 \mathrm{E}+10$ cycles and high-cycle fatigue (HCF) behavior in the regime from $10 \mathrm{E}+4$ to $10 \mathrm{E}+7$ cycles were investigated in the B-free and 0.1 mass $\%$ B-modified Ti-6Al-4V alloys.

A refined fully lamellar microstructure with a prior $\beta$-phase grain size on the order of $100 \mu \mathrm{m}$ and consequently refined colonies with a diameter of $30 \sim 70 \mu \mathrm{m}$ each were obtained by the addition of 0.1 mass $\%$ B. In contrast, there was no morphological difference in equiaxed microstructures between the B-free and 0.1 mass\% B-modified alloys, and an $\alpha$ grain size of $\sim 8 \mu \mathrm{m}$ was obtained for both.

The VHCF and HCF behaviors of the 0.1 mass $\%$ Bmodified alloy were found to be highly dependent on both microstructures and the level of applied stress. In the VHCF regime where applied stress is well below the conventional fatigue threshold, the B-free and 0.1 mass $\%$ B-modified alloys exhibited the same fatigue strength, i.e., the same fatigue lifetime, within the same microstructure. The set of VHCF data for the B-free and B-modified alloys with equiaxed microstructures was ranked more highly than that for the B-free and B-modified alloys with lamellar microstructures. The overall trend of the HCF lifetime, i.e., the $\mathrm{HCF}$ strength, was that the addition of $0.1 \mathrm{mass} \% \mathrm{~B}$ had either a favorable effect or no influence on the fatigue life depending on the applied stress level. Above a certain stress level that corresponds to a cycle regime of up to about $10 \mathrm{E}+6$ cycles for a lamellar microstructure and up to about $10 \mathrm{E}+7$ cycles for an equiaxed microstructure, the fatigue life was remarkably prolonged by the addition of 0.1 mass $\% \mathrm{~B}$. This improved HCF strength was caused by the inhibitory effect of TiB against the expansion of the fatigue initiation area. However, the favorable effect of $\mathrm{B}$ was gradually diminished with decreasing stress levels, and the HCF strengths of the B-free and 0.1 mass \% B-modified alloys were coincident below a certain applied stress level in each of microstructures. One possible explanation might be that when the application of stress during the fatigue test is sufficiently high, the impact between the front of the moving fatigue crack and a TiB or streaks of TiB will generate greater backward force to the moving fatigue crack, thereby slowing the expansion of the fatigue crack front, which in turn would prolong the HCF life.

\section{REFERENCES}

1) V. Kazymyrovych: Karlstad University Studies, (2009:22) 1-33.

2) C.J. Szczepanski, S.K. Jha, J.M. Larsen and J.W. Jones: Metall. Mater. Trans. A 39 (2008) 2841-2851.

3) Y. Furuya, H. Hirukawa, T. Kimura and M. Hayasi: Metall. Mater. Trans. A 38 (2007) 1722-1730.

4) B. Pyttel, D. Schwerdt and C. Berger: Int. J. Fatigue 33 (2011) 49-58

5) Y. Furuya and E. Takeuchi: Mater. Sci. Eng. A 598 (2014) 135-140.

6) A. Nikitin, T. Palin-Luc and A. Shanyavskiy: Int. J. Fatigue 93 (2016) 318-325.

7) W. Li, H. Zhao, A. Nehila, Z. Zhang and T. Sakai: Int. J. Fatigue 104 (2017) 342-354.

8) X. Pan, H. Su, C. Sun and Y. Hong: Int. J. Fatigue 115 (2018) 67-78.

9) S. Tamirisakandala, R.B. Bhat, J.S. Tiley and D.B. Miracle: Scr. Mater. 53 (2005) 1421-1426.

10) B. Cherukuri, R. Srinivasan, S. Tamirisakandala and D.B. Miracle: Scr. Mater. 60 (2009) 496-499.

11) L. Huang, F. Kong, Y. Chen and S. Xiao: Mater. Sci. Eng. A 560 (2013) 140-147.

12) L. Huang, Y. Chen, F. Kong, L. Xu and S. Xiao: Mater. Sci. Eng. A 577 (2013) 1-8.

13) M.J. Bermingham, S.D. McDonald and M.S. Dargusch: Mater. Sci. Eng. A 719 (2018) 1-11.

14) S. Tamirisakandala, R.B. Bhat, J.S. Tiley and D.B. Miracle: J. Mater. Eng. Perform. 14 (2005) 741-746.

15) R. Srinivasan, D. Miracle and S. Tamirisakandala: Mater. Sci. Eng. A 487 (2008) 541-551.

16) R. Srinivasan, M.D. Bennett, S. Tamirisakandala, D.B. Miracle, K.-O. Yu and F.S. Sun: J. Mater. Eng. Perform. 18 (2009) 390-398.

17) M. Hagiwara, T. Kitaura, Y. Ono, T. Yuri, T. Ogata and O. Kanou: Mater. Trans. 53 (2012) 1486-1494.

18) M. Hagiwara, T. Kitaura, Y. Ono, T. Yuri, T. Ogata and S. Emura: Mater. Trans. 53 (2012) 1138-1147.

19) I. Sen, K. Gopinath, R. Datta and U. Ramamurty: Acta Mater. 58 (2010) 6799-6809.

20) S. Roy, A. Sarkar and S. Suwas: Mater. Sci. Eng. A 528 (2010) 449458.

21) S. Roy, S. Suwas, S. Tamirisakandala, D.B. Miracle and R. Srinivasan: Acta Mater. 59 (2011) 5494-5510.

22) M. Hagiwara, A. Araoka and S. Emura: Metall. Mater. Trans. A 35 (2004) 2161-2170.

23) M. Hagiwara, Y. Kaieda, Y. Kawabe and S. Miura: ISIJ Int. 31 (1991) 922-930.

24) M. Hagiwara, T. Kitashima and S. Emura: Mater. Sci. Eng. A 727 (2018) 43-50.

25) H. Yokoyama, O. Umezawa, K. Nagai, T. Suzuki and K. Kobuko: Metall. Mater. Trans. A 31 (2000) 2793-2805.

26) O. Umezawa and K. Nagai: ISIJ Int. 37 (1997) 1170-1179.

27) D. Eylon and J.A. Hall: Metall. Trans. A 8 (1977) 981-990. 